\title{
Impact of Ozone Used-Alone and Coagulation Aid Treatment on The Reduction of Trihalomethanes Components
}

\author{
Heba A. Yousif ${ }^{1, a^{*}}$ and Nawar O. A. AL-Musawi ${ }^{1, b}$ \\ ${ }^{1}$ Department of Civil Engineering, University of Baghdad, Baghdad, Iraq \\ ah.yousif1101@,coeng.uobaghdad.edu.iq, bnawar.o@coeng.uobaghdad.edu.iq
}

\begin{abstract}
The whole research paper examines the impact of ozone as either a just use-alone and coagulation benefit, mainly upon the reduction of dissolved organic carbon from the water with a moderate rate of DOC $10.75 \mathrm{mg} / \mathrm{land} \mathrm{CaCO}_{3}$ calcium hardness $300 \mathrm{mg} / \mathrm{l}$. A raw water sample has been taken from the Tigris River (Baghdad, Iraq) was being adopted in research work. The performance of ozone therapy has been assessed by calculations of DOC, DOC quantities, $\mathrm{UV}_{254}$, as well as total trihalomethane (TTHM). Research findings have shown that with $0.9 \mathrm{mg} \mathrm{O} / \mathrm{mg}$ DOC ozone use-alone, approximately $60 \% \mathrm{UV}_{254}$ reduction and approximately $28 \%$ DOC reduction will occur.DOC fractionation analysis indicates that within the water samples, ozone could alter the composition of DOC, transform the hydrophobic fractions toward hydrophilic fractions and reduce TTHM. Ozone was also responsible for a significant reduction in particle stability as well as the dissolved calcium content. Improved water flocculation and improved DOC removal were triggered by these simultaneous ozonation effects. This resulted in a decrease in the coagulant dosage while the dosage of ozone is considerably higher over $0.3 \mathrm{mg} \mathrm{O} / \mathrm{mg}$ DOC has added before ferric sulfate coagulation. The pre-ozonation coagulation method also accomplished favorable removal of TTHM with all tested ozone doses ( 0 to $0.9 \mathrm{mg} \mathrm{O} / \mathrm{mg}$ DOC), resulting in lower TTHM during preozonated coagulated waters unlike those through related ozonated waters.
\end{abstract}

Keywords: Dissolved organic carbon; ozone; fraction; trihalomethane; coagulation.

\section{Introduction}

Existing compliance disinfection standards (DBPs), like trihalomethanes, have been enabled water purification plants to enhance the elimination of NOM. Usually, natural organic matter is calculated by organic dissolved carbon.DOC elimination is indeed a significant issue. Large concentrations of the sampled waters were found in the hydrophobic acid fraction (HPOA) containing mainly humic substances in this DOC fraction. The humic compounds get the main responsibility to formulate THMs [1,2]. Consequently, removing the humic portion seems to be the main factor for lowering amount of chlorine disinfection by-products in purified water. The precursor THMs can be extracted from water by different physical and chemical processes, like coagulation/ flocculation, advanced oxidation, adsorption, activated carbon, ion-exchange as well as biological degradation. The widely common of most of these methods are chemical coagulation. However, water DOC can often not be reduced to small concentrations to prevent THMs from forming through coagulation [3]. To ensure maximum the removal of DOC through coagulation, $\mathrm{pH}$ adjustment was therefore needed; this would be very expensive for waters with high $\mathrm{pH}$ and alkalinity [4]. The goals from this research are:

- To research the influence of ozone throughout this particular source of water on DOC and various fractions of DOC.

- To explore the impact of ozonation upon the total capacity of the samples to form THMs.

- To explore the impact of ozone as a support to the coagulation of ferric sulfate, aimed at a significant decrease in DOC and TTHM.

- It is important to examine the impact of calcium concentration on ozone-induced coagulation 


\section{Ozone Employment in Water Purification}

With the assistance of high oxidation potential, the use of ozone through water purification has been popular. Molecular $\mathrm{O}_{3}$ is a powerful oxidant; many powerful oxidants, hydroxyl radicals $(\mathrm{OH})$, can be formed as it dissociates into water ozone [5]. As an efficient approach to eliminating components of disinfection by-products existing in treated water sources, ozonation was identified. Surveys have shown, even then, that ozonation might have an adverse impact in some cases [6,7]. Consequently, with each particular water source, the impact of ozonation mostly on the qualities of the water supply as well as its ability for the formation of DBPs needs to be analyzed. It was because the NOM seems to have a complicated system and that it is not practical to directly compare the impact of ozone on the NOM from various sources.

The impact of ozone on the mechanism of chemical coagulation. The studies upon the impacts of ozone as a coagulation aid seem to be complicated. Many studies have established situations in which ozone upgraded the removal of DOC with the aid of subsequent coagulation and effectively decreased the creation of THMs. On the contrary, several studies have presented that pre-ozonation doesn't minimize the coagulant dose. A variety of simultaneous processes that take place during this treatment phase may explain the contradictory researches on the ozone impact on coagulation. Most of these pathways maintain certain impacts, while others would have a detrimental effect on later coagulation treatment. By recognizing these pathways, ozone-enhanced coagulation can be improved [8]. As ozone is being adapted in water treatment as a pre-oxidant, multiple hypothesized mechanisms were mentioned; greatly help through particle destabilization as well as aggregation [9]:

1) The quantity of oxygenated functional groups, like carboxylic acid, can be increased by ozone, resulting in contact as well as complexity with coagulant cations or cations that are generally available, including calcium. These findings contribute to assisted coagulation/flocculation in ozonated waters.

2) Ozone can decrease the stabilization of organic particle coatings, cause organic desorption, and decrease the attraction force between all the particles.

3) Ozone could already polymerize meta-stable organics and, through bridging reactions, lead to particle aggregation.

4) Ozone could even split organo-metal complexes, causing coagulants to be generated in situ.

The effect of ozone on coagulation is defined either by ozone dosage, coagulation requirements (coagulant type as well as dosage), and water supply nature (DOC variety, intensity, hardness, and alkalinity) as the primary factors.

The purpose of hardness in ozone upgraded coagulation. Calcium has been described as an important component in ozone-induced particles destabilization. This one has been observed that before coagulation, ozonation helps waters containing moderate to high calcium hardness levels. Besides this, ozone-induced particle destabilization, as well as agglomeration, happens just in the cases of excess calcium. Chandrakanth [10] often observed ozone-developed coagulation whenever the water source would have an amount of calcium hardness greater than $100 \mathrm{mg} / \mathrm{C} \mathrm{CaCO}_{3}$. Research has shown that ideal ozone-induced particle destabilization may happen in waters containing calcium hardness-to-total organic carbon (TOC) ratios of $>25 \mathrm{mg} \mathrm{CaCO} 3 / \mathrm{mg}$ DOC. Calcium does have incredibly strong tend to build stronger compounds with oxygen-containing functional groups. The ozonation of organic water substances will generate oxygen-rich compounds, like carboxyl groups, leading to higher complexity for the pair aqueous NOM as well as particle-sorbet calcium natural organic carbon. Calcium also could neutralize the anionic surface charge of organic particles which could result in a decrease in particle stability through the reduction of surface charge [11]. This technique is essential as long as the water origin has a high level of calcium hardness [12]. This research leads to the reporting of the impact of ozone on the reduction by coagulation of TTHM precursors from the single water supply. In addition to high calcium hardness, Tigris water has 
moderate to high DOC. This water source would be a perfect choice for such a study about just how ozone's function in the chemical coagulation process can be influenced by water quality.

\section{Materials and Methods}

The material which used as a coagulant was ferric sulfate in this research.

Water Sources. The water sample investigated in this study was obtained from Tigris River at Baghdad had also moderate to high concentrations of DOC, high alkalinity, and hardness. Furthermore, there's often a high $\mathrm{pH}$ of 8 throughout the water sample, see Table 1.

Table 1. The general characteristics of water's supply.

\begin{tabular}{|c|c|c|c|c|c|c|}
\hline $\begin{array}{c}\text { Water } \\
\text { Sample }\end{array}$ & $\mathbf{p H}$ & Turbidity & $\mathbf{U V}_{\mathbf{2 5 4}}\left(\mathbf{c m}^{-\mathbf{1}}\right)$ & DOC $(\mathbf{m g} / \mathbf{l})$ & Hardness (mg/l) & SUV $_{\mathbf{A}}(\mathbf{l} / \mathbf{m g} . \mathbf{m})$ \\
\cline { 2 - 7 } & 8.3 & 100.6 & 0.470 & 10.75 & 300 & 4.37 \\
\hline
\end{tabular}

Experimental Setup. An apparatus had to be designed and constructed to treat the water with ozone i.e., an ozone contact chamber. The apparatus model was predicated on the contact chamber used by Pryorin the laboratory [13]; semi-batch ozonation procedures (continuous gas admission as well as static liquid volume) have been performed. $\mathrm{O}_{3}$ has been formed by a testing ozone generator using the method of corona discharge with cool and dry surrounding air as the ozone-producing feed gas. For permitting the ozone to spread in the water, a glass diffuser has been used. The ozone reactor has been designed of Plexiglass with a height of 75 and an inner diameter of $6 \mathrm{~cm}$. The glass tube was $3 \mathrm{~L}, 1.2 \mathrm{~m}$ long, and had a diameter of $6 \mathrm{~cm}$ inside. All the reactor materials being used are ozoneresistant. The system for setup for pilot ozonation can be seen in Fig. 1. The iodometric method DBD colorimetric method, as described in the instruction manual for multi direct live bond devices, calculated the ozone production from of the generator as well as ozone concentration in the off-gas. After each ozonation run, nitrogen gas must have been pumped into the water sample for a minimum of 10 minutes to remove the residual ozone gas. In this study, the dosage of Ozone indicated the transferred $\mathrm{O}_{3}$ dosage (variation between the density of ozone added as well as the density of ozone in the off-gas), which mostly varied from (0 to $0.9 \mathrm{mg} \mathrm{O} / \mathrm{mg} \mathrm{DOC}$ ) in this research.

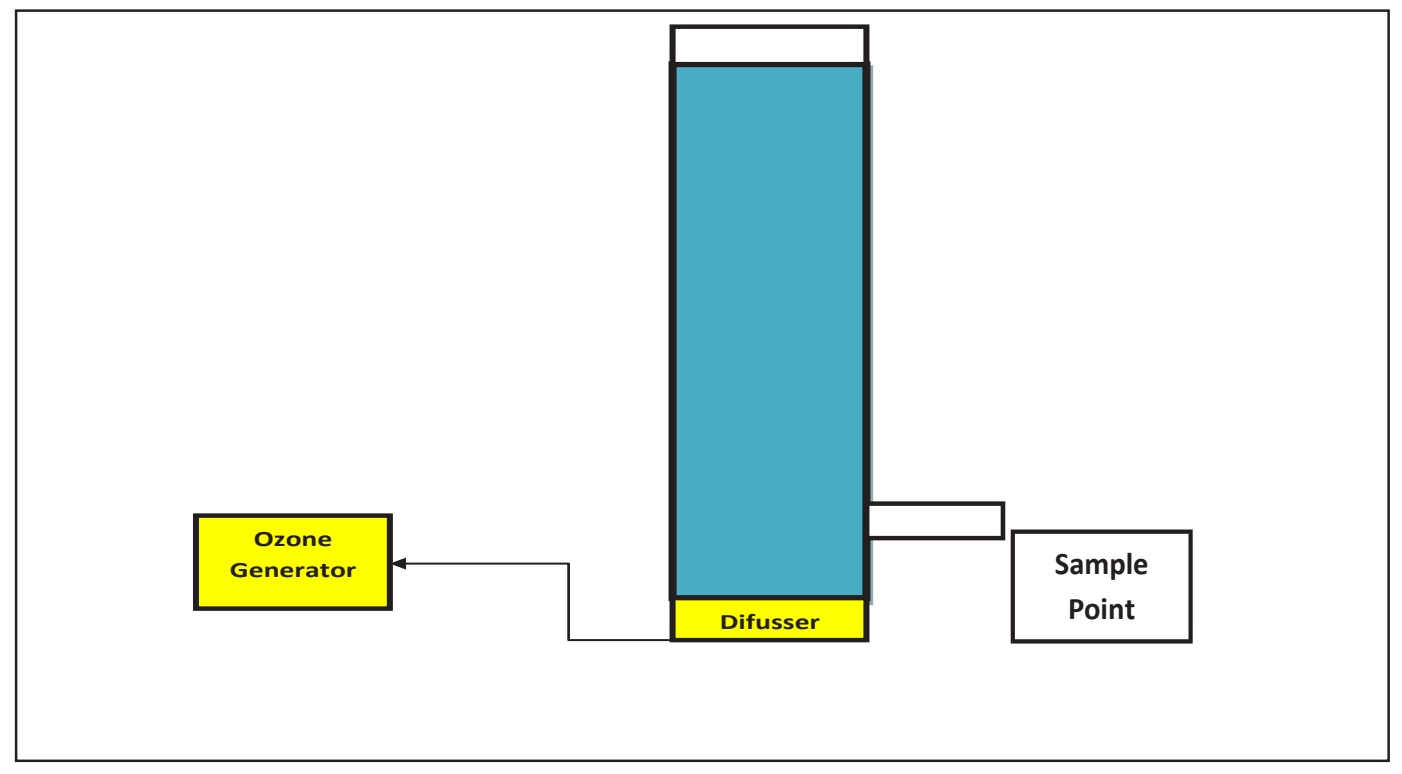

Figure 1. Graphical model of ozone contact chamber with dimensions $=$ internal diameter of $6 \mathrm{~cm}, 2$ $\mathrm{m}$ high, and a volume of 3 liters.

Experimental procedure. There were two different groups of testing accomplished: 
The stand-alone ozone effect. Raw water was ozonated at 6 separate concentrations to examine the impacts of stand-alone ozone on the examined water: $0,0.10,0.3,0.40,0.60$, and $0.90 \mathrm{mg}$ $\mathrm{O}_{3} / \mathrm{mg}$ DOC.

The influence with ozonation mostly on mechanism of chemical coagulation. The water source has been ozonated $(0.3,0.6$, and $0.9 \mathrm{mg} \mathrm{O} / \mathrm{mg}$ DOC) as well as later coagulated with ferric sulfate in order to research the impact of ozone on coagulation. Coagulation studies have been conducted at room temp. By using a traditional approach jar test. The ferric sulfate coagulant dose was within the limit of (0-25) $\mathrm{mg} / \mathrm{l}$. In each bottle, one liter of raw water was added. Then, with a gradual mixing at $25 \mathrm{rpm}$, the specimens were examined to rapid mixing for 2 minutes and $100 \mathrm{rpm}$ then 30 minutes, allowing the flocs to settle for 45 minutes before the mixing was completed. With a scientific grade of $0.1 \mathrm{M}$ hydride solution $(\mathrm{NaOH})$ or0.1 M sodium hydroxide solution $(\mathrm{NaOH})$ or $0.1 \mathrm{M}$ hydrochloric acid $(\mathrm{HCl})$, the $\mathrm{pH}$ has been optimized to the required value.

Analytical Methods. The efficacy of ozonation was being analyzed by dissolved organic carbon calculation, $\left(\mathrm{UV}_{254}\right)$, DOC fractions, and trihalomethane to differentiate the technique of ozone effects. Samples have been filtered via $0.45 \mathrm{~mm}$ nitrocellulose filter paper and dissolved organic carbon levels will be calculated by a multi-N/C 3100 total organic carbon analyzer (Analyticjena, Italy). The UV-Vis (UV-9200, Biotech Engineering Management, and the UK) spectrophotometer model with a $1-\mathrm{cm}$ long quartz cell was used for ultraviolet absorbance calculation at $254 \mathrm{~nm}$ wavelength. A water-aromaticity indicator of the NOM is the SUVA (Specific Ultra-Violet Absorbance). The $\mathrm{pH}$ was accounted for in compliance with the Standard Method using the Horiba U-10 pH meter. Alkalinity results of samples were identified by using method No. 2320B. Ratpukdi established the DOC fractionation method applied in this study employing solid-phase extraction (SPE) particularly in comparison to the classic resin fractionation techniques [14].

Leenheer founded that the SPE approach effectively eliminates any necessity for long resin preparation periods and expensive devices, performing the whole process an ideal alternative to conventional methods of resin separation. [15]. Even before extraction, both solutions were filtered using a $0.45 \mathrm{~mm}$ nitrocellulose laboratory filter and then have taken to room temperature. To divide DOC into six isolated fractions, three Bond Elute ENV cartridges have been used in this procedure: hydrophilic neutral (HPIN), hydrophilic acid (HPIA), hydrophobic acid (HPOA), hydrophilic base (HPIB), hydrophobic base (HPOB), and hydrophobic neutral: one Phenomenex Strata X-AW Phenomenex and one Strata XC cartridge (Phenomenex, Torrance, California). The same procedure was described in reference [14]. The readings of the formation of TTHMs potential were carried out along with Standard Methods 5710B; descriptions of this process are being defined by Gross [16]. In each filtered sample, $50 \mathrm{mg} / 1$ sodium hypochlorite has been implemented to make sure that adequate chlorine was available to react with the organics. By using a phosphate buffer, samples would be buffered to $\mathrm{pH}=7$. Sample vials have been sealed with closed caps and held throughout 7 days under $4^{\circ} \mathrm{C}$ in the dark. All the samples were analyzed for free chlorine $>1.0 \mathrm{mg} / 1$ (3-5 mg/l) after 7 days, suggesting that all TTHM formation transformations have pushed to completion.

\section{Results and Discussion}

General Water Quality. Table 2 shows the common quality of the raw water. The sample of water shows a high level of hardness and DOC. The value of 4.70 SUVA shows that the water's character is much more hydrophobic [17] as given in Table 2. The water sample's DOC extraction data are summarized in table 3 . For the sample, the fractionation results showed that hydrophobic fractions are responsible for more than $75 \%$ of DOC, and the hydrophobic acid fraction is correlated with more than $55 \%$ of organic carbon as shown in Table 3 . This primary observation might be consistent with the fact which high-DOC waters in nature tend to be even more hydrophobic [18]. The lowest concentration of hydrophobic base fraction was in this source water $(1.7 \%)$ which is consistent with earlier studies having lower hydrophobic base concentrations in much natural water $[15,19]$. 
Table 2. Guidance for the nature of natural organic matter by the value of SUVA.

\begin{tabular}{|c|c|}
\hline SUVA value (I/mg.m) & Nature of NOM \\
\hline$<2$ & Low molecular weight, Low hydrophobicity, Mostly non-humic. \\
\hline $2-4$ & A mixture of molecular weights, Mixture of hydrophobic and hydrophilic NOM. \\
\hline$>4$ & $\begin{array}{c}\text { High hydrophobicity. Mostly aquatic humic. A mixture of aquatic Humic and } \\
\text { other NOM. High molecular weight, Mixture of aquatic humic and other NOM. }\end{array}$ \\
\hline
\end{tabular}

Table 3. The DOC composition of the water's sample.

\begin{tabular}{|c|c|c|}
\hline Fraction & Concentration (mg/l) & DOC (\%) \\
\hline Hydrophobic base (HPOB) & $0.18 \pm 0.04$ & 1.7 \\
\hline Hydrophobic neutral (HPON) & $2.52 \pm 0.05$ & 23.4 \\
\hline Hydrophobic acid (HPOA) & $6.00 \pm 0.06$ & 55.8 \\
\hline Hydrophilic base (HPIB) & $0.3 \pm 0.04$ & 2.8 \\
\hline Hydrophilic acid (HPIA) & $0.7 \pm 0.03$ & 6.5 \\
\hline Hydrophilic neutral (HPIN) & $1.05 \pm 0.05$ & 9.8 \\
\hline Total & $10.75 \pm 0.04$ & 100 \\
\hline
\end{tabular}

\section{Impact of Ozone Aquatic Organic Carbon When Use Alone}

DOC and $\mathbf{U V}_{254}$. Up to $28 \%$ of the DOC was removed just at a dosage of $0.9 \mathrm{mg} \mathrm{O} / \mathrm{mg}$ DOC. At the lower ozone doses, reduced DOC removals (i.e., $12 \%$ as well as $19 \%$ at 0.3 and $0.4 \mathrm{mg} \mathrm{O} /$ $\mathrm{mg}$ DOC respectively) were obtained. The greater removal of DOC at the higher dose of ozone can be described as follows; a rise in the dosage of ozone provides more usable molecules of ozone and hydroxyl radical, created by the decomposition of ozone, degrades recalcitrant organic compounds to smaller molecules that are more hydrophilic and degradable, leading to an increase in the removal of organic carbon [14]. $\mathrm{UV}_{254}$ is widely had to denote the relative quantity of aromatic and/or unsaturated DOC carbon. A decrease in $\mathrm{UV}_{254}$ was observed for all ozone doses, suggesting the oxidation of aromatic and/or unsaturated carbon molecules that is consistent with earlier results presented [19, 20]. Figure 2 indicates that compared to the DOC elimination, the $U_{254}$ reduction was higher. This indicates incomplete mineralization of organic molecules degraded from aromatic and/or unsaturated organics [14]. The decrease of DOC by ozonation bases on the overall properties studied, like the composition and concentration of DOC, so it cannot be contrasted with different sources of water. After all, the results obtained from this study could be contrasted with some published research displaying a reduction in DOC ranging from (5-25) \% under a normal ozone dose of 0.4-1 mg O $3 / \mathrm{mg}$ DOC [21].

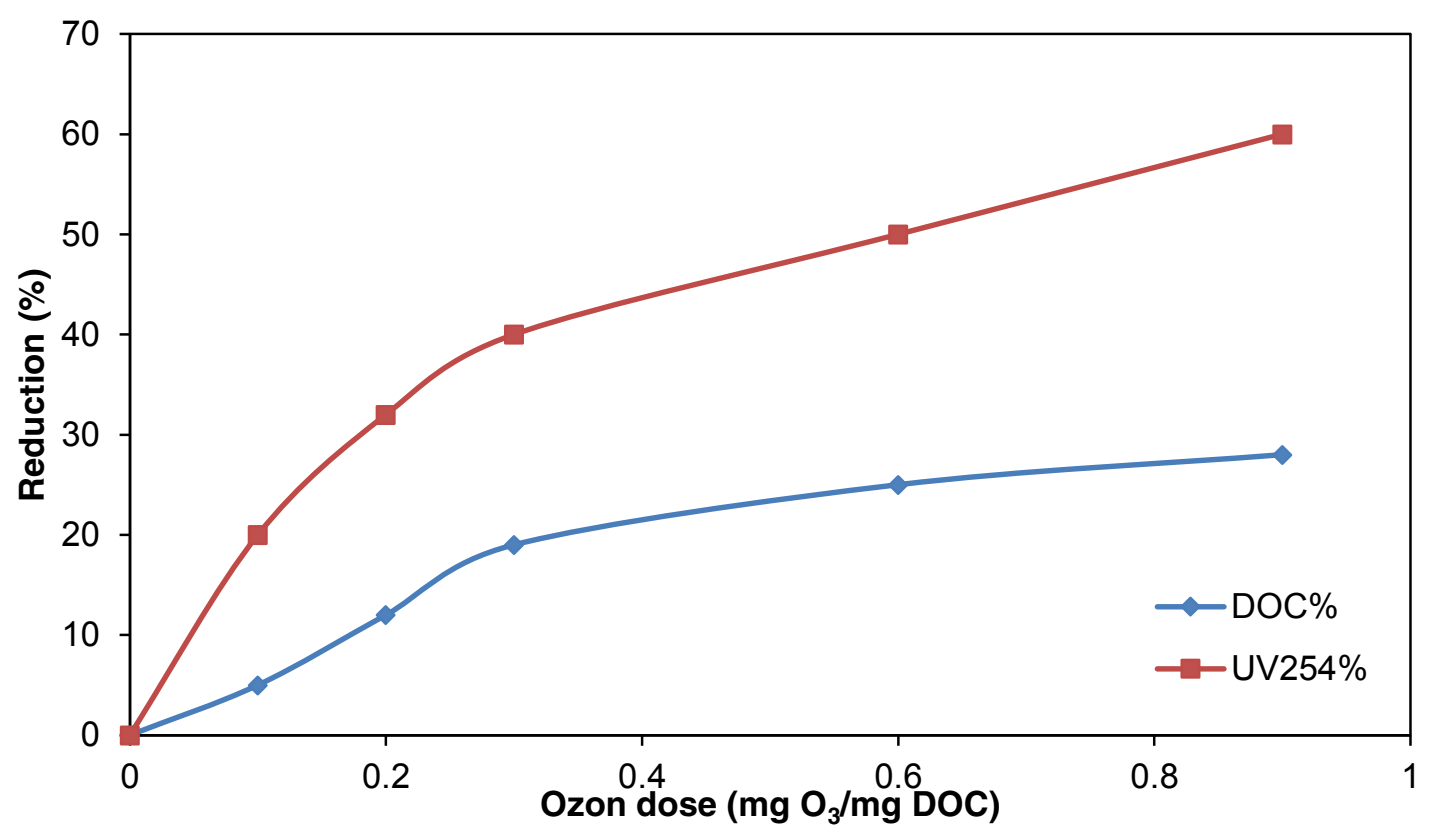

Figure2.Removal of Doc and UV for water samples at different ozone doses. 
Impact of ozone on DOC composition in water. The impact of $\mathrm{O}_{3}$ on Dissolved organic carbon mixtures, widely recognized as a major contributor of THMs would be effective in the reduction of such disinfection by-products. So as to analyze the impact of ozone of individual DOC fractions, the DOC of ozonated and raw water with different separate doses $(0.3,0.6$, and $0.9 \mathrm{mg} \mathrm{O} / \mathrm{mg}$ DOC) was extracted, see Table 4. The sample characteristics of a DOC are transformed by ozone to be more hydrophilic as shown in Fig. 3. The presence of hydrophobic fractions of DOC decreases once the ozone dosage increases significantly, while the concentration of hydrophilic fractions, especially HPIN, increases. These results are consistent with previous studies [3]. In addition, ozone was considered highly constructive in the reduction (or conversion) of the HPOA fraction [3].

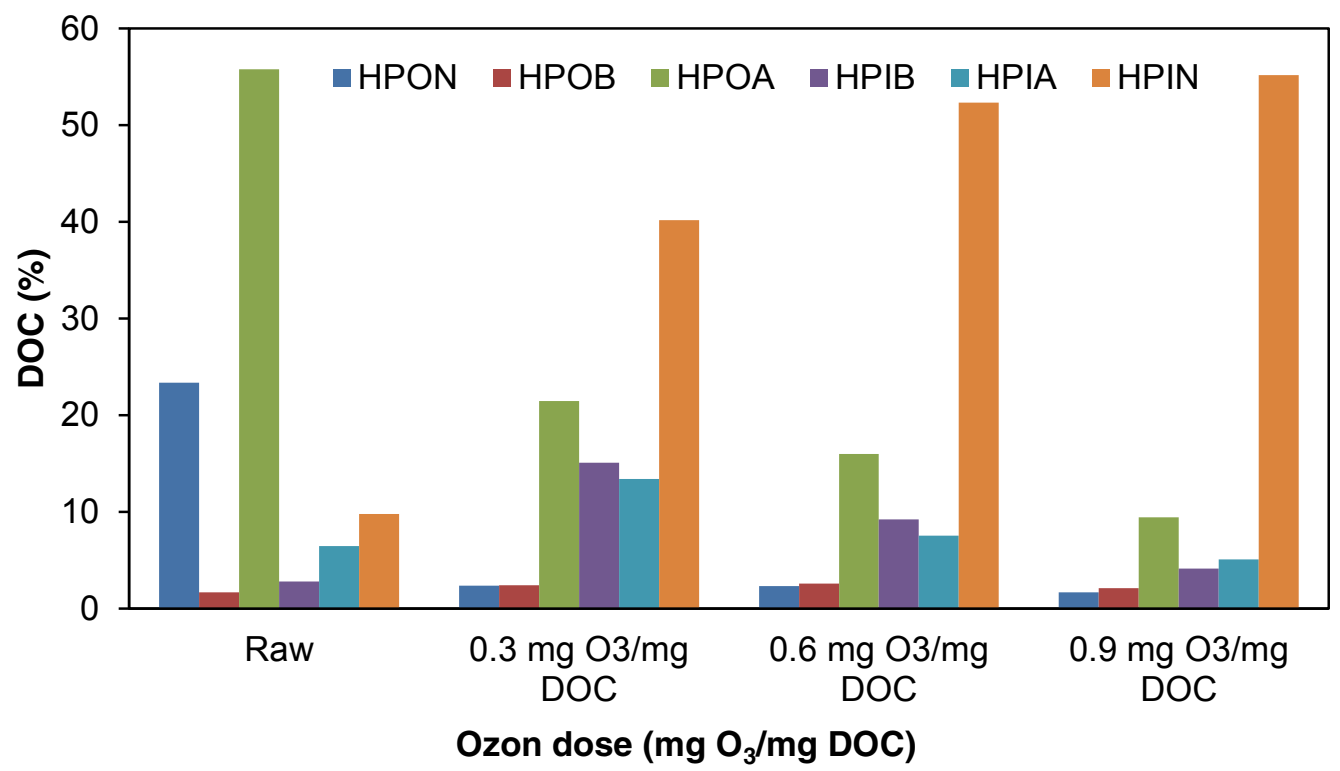

Figure 3. DOC fractions remaining in the sample after ozone has been applied.

Table 4. DOC fractions after ozone applied (\% DOC remaining).

\begin{tabular}{|c|c|c|c|c|c|c|}
\hline \multirow{2}{*}{ Sample } & \multicolumn{6}{|c|}{ \% DOC } \\
\cline { 2 - 7 } & HPOA & HPON & HPOB & HPIN & HPIA & HPIB \\
\hline Raw & 55.8 & 23.4 & 1.7 & 9.8 & 6.5 & 2.8 \\
\hline $0.3 \mathrm{mgO}_{3} / \mathrm{mg} \mathrm{DOC}$ & 21.47 & 2.4 & 2.42 & 40.18 & 13.42 & 15.11 \\
\hline $0.6 \mathrm{mgO}_{3} / \mathrm{mg} \mathrm{DOC}^{2}$ DO & 16 & 2.33 & 2.61 & 52.34 & 7.55 & 9.23 \\
\hline $0.9 \mathrm{mgO}_{3} / \mathrm{mg} \mathrm{DOC}$ & 9.45 & 1.68 & 2.13 & 55.19 & 5.1 & 4.15 \\
\hline
\end{tabular}

Impact of ozone on the trihalomethane (TTHM). The impact of ozone on TTHM is given in Table 5. Usually, because of ozone dose has increased, THMFP dropped in value. The sample has a TTHM of $97.5 \mathrm{mg} / \mathrm{l}$. Ozonation lowered TTHM by up to $40 \%$ that is greater than the reduction in DOC (27\%) because Ozone can convert NOM from higher molecular weight organic compounds to lower molecular weight by-products. These by-products are less reactive with chlorines and result in a reduction of formation of THMs upon subsequent chlorination [22,23]. Many other authors noticed that TTHM could be decreased by $10-64 \%$ by ozone employment $(0.1-1 \mathrm{mg} \mathrm{O} / \mathrm{mg}$ DOC). The TTHM reductions also are within the rates recorded.

Table 5. TTHM for Baghdad raw and ozonated water specimens.

\begin{tabular}{|c|c|c|c|c|c|}
\hline Sample & Chloroform & Bromoform & DBCM & BF & THMFP \\
\hline $\mathrm{Raw}$ & 21.32 & 31.93 & 35.14 & 8.95 & 97.34 \\
\hline $0.3 \mathrm{mg} \mathrm{O} / 3 \mathrm{mg} \mathrm{DOC}$ & 20.62 & 30.88 & 33.93 & 8.66 & 94.09 \\
\hline $0.6 \mathrm{mg} \mathrm{O} / 3 \mathrm{mg} \mathrm{DOC}$ & 17.68 & 26.47 & 29.13 & 7.42 & 80.7 \\
\hline $0.9 \mathrm{mg} \mathrm{O}_{3} / \mathrm{mg} \mathrm{DOC}^{2}$ & 12.03 & 18.00 & 19.82 & 5.05 & 54.9 \\
\hline
\end{tabular}




\section{Impact of Ozonation on Chemical Coagulation Process}

Dissolved organic carbon removal. The results of pre-ozonation upon reduction of these examined sample dissolved organic carbon by coagulation by ferric sulfate has shown in Figure 4. Different $\mathrm{O}_{3}$ dosages $(0.3,0.6$, and $0.9 \mathrm{mg} \mathrm{O} / \mathrm{mg}$ DOC) were used as well as three $\mathrm{pH}$ doses $(6,7$, and 8) were added during ozonation. The data suggest that ozonation improved DOC disposal by coagulation. At a higher ozone concentration, the significant outcome of pre-ozonation seems to be more noticeable. The application of ozone made it possible to significantly eliminate DOC at lower coagulant dosages, see Figures 4 to 6 . The above results were consistent test results that show the efficiency of coagulation by itself is relatively weak at a low coagulant dose [24]. Regardless of the dosage of ozone, the best incremental DOC reduction has been obtained at a dose of $25 \mathrm{mg} / \mathrm{l}$.

Figures 4 to 6 demonstrates that DOC reduction through coagulation at ozone dose levels of 0.3 $0.9 \mathrm{mg} \mathrm{O} 3 / \mathrm{mg}$ DOC for this sample was improved by pre-ozonation. The ozone dosage of $0.3 \mathrm{mg}$ $\mathrm{O}_{3} / \mathrm{mg}$ DOC did not even have a major impact on the reduction of the DOC. As shown in Figures 4 to $6, \mathrm{pH}$ could have a major effect on the reduction of DOC by ozonation. The highest DOC removals obtained at $\mathrm{pH} 6(45 \%, 50 \%$, and $65 \%$ of DOC removal at $0.3,0.6$, and $0.9 \mathrm{mg} \mathrm{O} / \mathrm{mg} \mathrm{DOC}$, respectively). For such ozone doses, DOC reduction decreased dramatically as the $\mathrm{pH}$ was going to grow to 7 and 8 since higher $\mathrm{pH}$ leads to more $\mathrm{OH}^{-}$so this speed up the decomposition of ozone to $\mathrm{OH}^{-}$and thus reduces the direct reaction between both the dissolved compounds and the ozone. The results demonstrate the previous reports reporting a high degree of similarity that DOC extraction efficiency in coagulation of related water sources, as well ozone supported increased as $\mathrm{pH}$ decreased $[4,14]$.

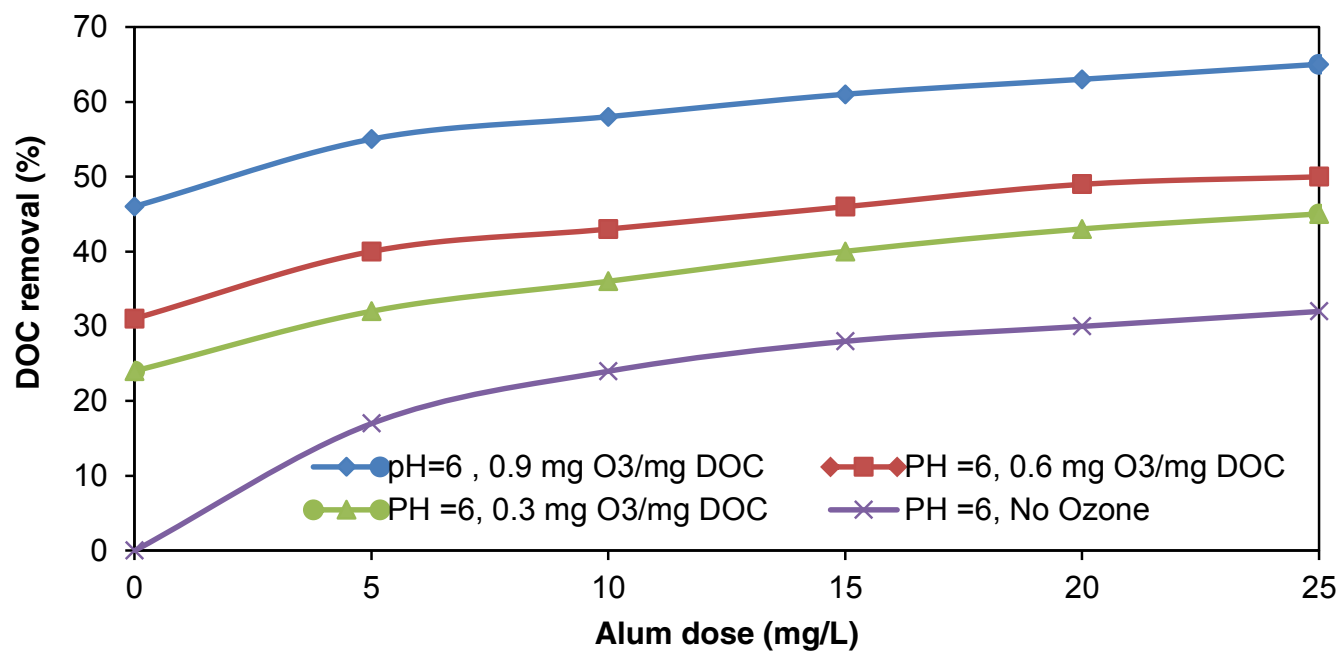

Figure 4. Removal of DOC for water samples at $\mathrm{pH}=6$ and coagulant values.

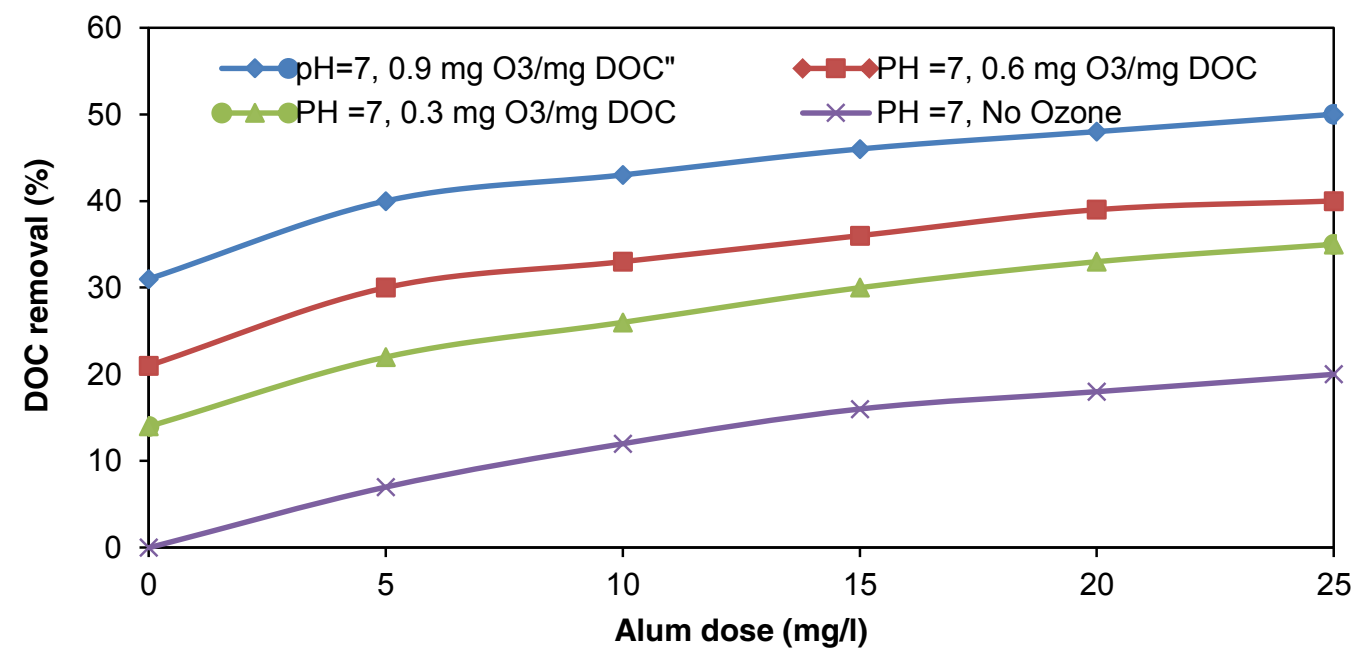

Figure 5. Removal of DOC for water samples at $\mathrm{pH}=7$ and coagulant values. 


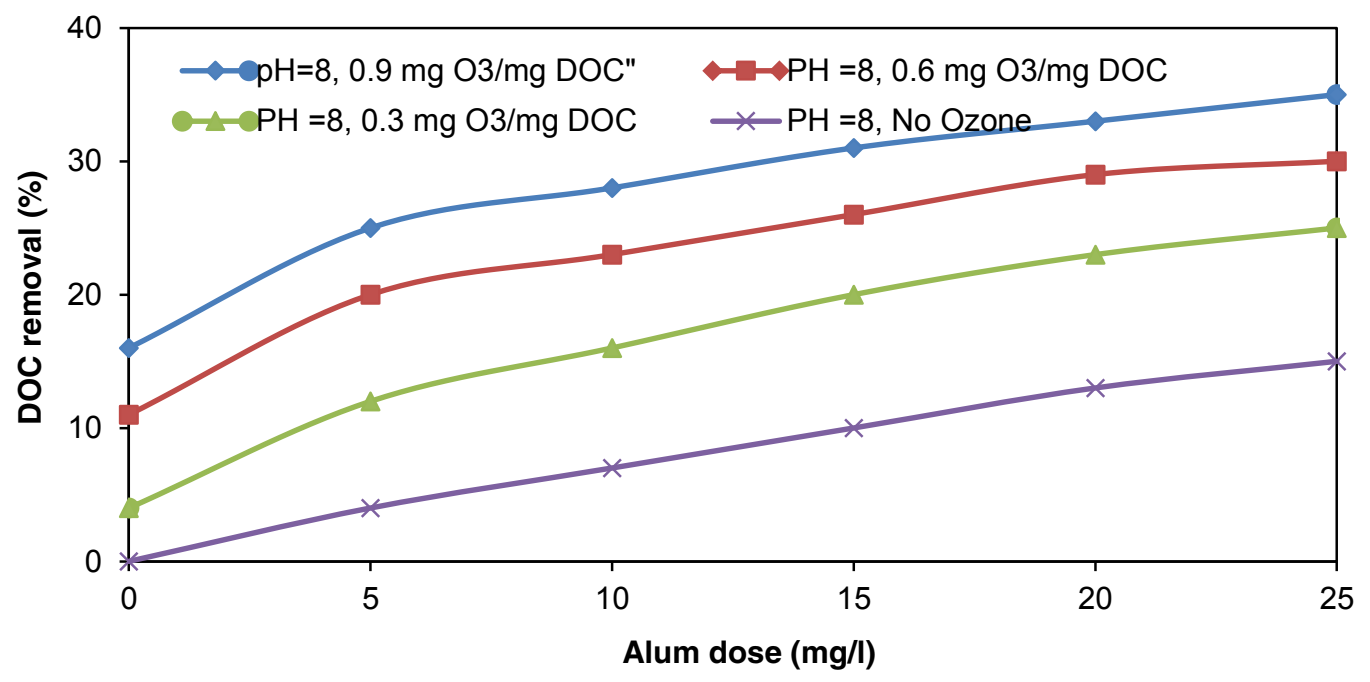

Figure 6. Removal of DOC for water samples at $\mathrm{pH}=8$ and coagulant values.

Impact of both pre-ozonation-coagulation on the trihalomethane. The impact of the preozonation, preceded by coagulation mostly on the decrease of TTHM also for water sample, can be seen in Table 6. For non-ozonated and ozonated tests, the TTHM of water coagulated at pH 6 and a coagulant dose of $25 \mathrm{mg} / 1$ was calculated. Due to negligible variations in DOC removal at coagulant doses greater than $25 \mathrm{mg} / \mathrm{l}$, this dose of coagulant was used. The results indicated that for all of the ozone doses measured, the decrease of TTHM was accomplished by the pre-ozonation-coagulation approaches. The coagulated raw water had a TTHM of $88.21 \mathrm{mg} / \mathrm{l}$ as shown in Table 6 . The rise in ozone dosage caused an increase in TTHM decrease. Considering those findings in Table 6 , it could be observed that pre-ozonation, accompanied by coagulation, data also in a greater reduction of TTHM instead of just ozonation alone.

Table 6. Impact of pre-ozonation-coagulation on TTHM elimination.

\begin{tabular}{|c|c|c|c|c|c|}
\hline Sample & Chloroform & Bromoform & DBCM & BF & THMFP \\
\hline $0.0 \mathrm{mg} \mathrm{O}_{3} / \mathrm{mg} \mathrm{DOC}$ & 18.41 & 29.33 & 33.32 & 7.15 & 88.21 \\
\hline $0.2 \mathrm{mg} \mathrm{O}_{3} / \mathrm{mg} \mathrm{DOC}$ & 14.83 & 22.21 & 25 & 6.22 & 68.26 \\
\hline $0.6 \mathrm{mg} \mathrm{O}_{3} / \mathrm{mg} \mathrm{DOC}$ & 12.27 & 18.38 & 20.23 & 5.15 & 56.03 \\
\hline $0.8 \mathrm{~m} \mathrm{O} \mathrm{O}_{3} / \mathrm{mg} \mathrm{DOC}$ & 10.37 & 15.54 & 17.1 & 4.35 & 47.36 \\
\hline
\end{tabular}

\section{Conclusions}

The impact of work-alone ozonation and that as a coagulation additional aid for the reduction of all of byproduct THMs would be site-specific and as well as entirely based on the quality of water supply. From that whole research, the following conclusions were made:

- Ozone treatment for water with high DOC as well as calcium hardness can reduce DOC approximately to $28 \%$ and $\mathrm{UV}_{254}$ up to $60 \%$.

- Transformation of Dissolved organic carbon based on ozonation led to an increase in THM reduction up to $42 \%$.

- Ozonation just before coagulation improved removal at ozone dosage of 0.6 and $0.8 \mathrm{mg}$ Ozone $/ \mathrm{mg}$ DOC. The low ozone dosage of $0.2 \mathrm{mg}$ Ozone $/ \mathrm{mg}$ DOC didn't represent a considerable impact on DOC elimination. The maximum dissolved organic carbon removal was achieved at pH 6.

- Such improved removal of dissolved organic carbon might lead towards ozone-induced particle destabilization and calcium formation of the DOC complex, in particular: (a) transformation of the hydrophobic DOC fraction to hydrophilic fractions with the low attraction of particle adsorption, resulting in lower surface charge of the particle, as well as (b) increased calcium complexation with NOM components. 
- Trihalomethanes were also reduced by pre-ozonation coagulation, indicating a higher reduction of THMat higher ozone doses. For all the ozone doses measured, the THM in pre-ozonated coagulated water samples was lower than that in ozonated waters.

- It can be inferred from this analysis that ozonation before coagulation is advantageous for Baghdad water sources, which also has moderate to high concentrations of organic carbon, high calcium hardness in form of coagulant dosage reduction as well as THM decrease.

\section{References}

[1] Chow, A.T., Gao, S. and Dahlgren, R.A., 2005. Physical and chemical fractionation of dissolved organic matter and trihalomethane precursors: A review. Journal of Water Supply: Research and Technology-AQUA, 54(8), pp.475-507.

[2] Reckhow, D.A., Singer, P.C., Malcolm, R.L., 1990. Chlorination of humic materials: byproduct formation and chemical interpretations. Environmental Science \& Technology, 24(11), 16551664.

[3] Chiang, P.C., Chang, E.E., and Liang, C.H., 2002. NOM characteristics and treatabilities of ozonation processes. Chemosphere, 46(6), 929-936.

[4] Sadrnourmohamadi, M., Goss, C.D., and Gorczyca, B., 2013. Removal of DOC and its fractions from the high DOC and hardness surface waters of the Canadian Prairie. WST: Water Supply $13,864-870$.

[5] Brookman, R., 2010. Controlling bromate formation by conventional and innovative titanium dioxide photocatalysis. M.Sc. Thesis, Dalhousie University, Nova Scotia, Canada.

[6] Chowdhury, F.L., Berube, P.R., Mohseni, M., 2008. Characteristics of natural organic matter and formation of chlorinated disinfection by-products from two source waters that respond differently to ozonation. Ozone: Science and Engineering, 30(5), 321-331.

[7] Toor, R. and Mohseni, M., 2007. UV-H2O2 based AOP and its integration with biological activated carbon treatment for DBP reduction in drinking water. Chemosphere 66(11), 20872095.

[8] Currie, M., Graham, N., Hall, T., and Lambert, S., 2003. The effect of bicarbonate on ozoneenhanced particle removal in water treatment. Ozone: Science and Engineering, 25(4), 285-293.

[9] Reckhow, D.A., Singer, P.C., and Trussell, R.R., 1986. Ozone as Coagulant Aid. Recent Advances and Research Needs, 17-46.

[10] Chandrakanth, M.S., 1994. Effects of ozone on the colloidal stability of particles coated with natural organic matter. Ph.D. Thesis, University of Colorado Boulder, USA.

[11] Edwards, M. and Benjamin, M.M., 1992. Effect of preozonation on coagulant-NOM interactions. Journal-American Water Works Association, 84(8), 63-72.

[12] William, B.D. and Singer, P.C., 1989. Effects of natural organic matter and calcium on ozoneinduced particle destabilization. Journal-American Water Works Association, 81(6), pp.77-85.

[13] Pryor, M.J., Naidoo, P.S., Bahrs, P. and Freese, S.D., 2002. Ozone experience at Umgeni Water. In biennial conference of the Water Institute of Southern Africa.

[14] Ratpukdi, T., Rice, J.A., Chilom, G., Bezbaruah, A. and Khan, E., 2009. Rapid Fractionation of Natural Organic Matter in Water Using a Novel Solid-Phase Extraction Technique. Water Environment Research, 81(11), 2299-2308.

[15] Leenheer, J.A., 1981. Comprehensive approach to preparative isolation and fractionation of dissolved organic carbon from natural waters and wastewaters. Environmental science \& technology, 15(5), 578-587.

[16] Goss, C.D. and Gorczyca, B., 2013. Trihalomethane formation potential of DOC fractions isolated from two Canadian Prairie surface water sources. Water Science and Technology: Water Supply, 13(1), 114-122.

[17] Ghernaout, D., 2014. The hydrophilic/hydrophobic ratio vs. dissolved organics removal by coagulation-A review. Journal of King Saud University-Science, 26(3), 169-180. 
[18] Sharp, E.L., Parsons, S.A. and Jefferson, B., 2006. Seasonal variations in natural organic matter and its impact on coagulation in water treatment. Science of the Total Environment, 363(1-3), 183-194.

[19] Świetlik, J., Dąbrowska, A., Raczyk-Stanisławiak, U. and Nawrocki, J., 2004. Reactivity of natural organic matter fractions with chlorine dioxide and ozone. Water research, 38(3), 547558.

[20] Camel, V. and Bermond, A., 1998. The use of ozone and associated oxidation processes in drinking water treatment. Water Research, 32(11), 3208-3222.

[21] Tuhkanen, T.A., Kainulainen, T.K., Vartiainen, T.K. and Kalliokoski, P.J., 1994. The effect of preozonation, ozone/hydrogen peroxide treatment, and nanofiltration on the removal of organic matter from drinking water. Ozone: science \& engineering, 16(5), 367-383.

[22] Amy, G.L., Tan, L. and Davis, M.K., 1991. The effects of ozonation and activated carbon adsorption on trihalomethane speciation. Water Research, 25(2), 191-202.

[23] Kerc, A., Bekbolet, M. and Saatci, A.M., 2003. Effect of partial oxidation by ozonation on the photocatalytic degradation of humic acids. International Journal of Photoenergy, 5(2), 75-80.

[24] Saunier, B.M., Selleck, R.E. and Trussell, R.R., 1983. Preozonation as a coagulant aid in drinking water treatment. Journal-American Water Works Association, 75(5), 239-246. 